\title{
BOT0210, una herramienta de apoyo a la docencia. Experiencia de la Cátedra Tecnologías de la Información de la UNED, Costa Rica
}

BOT0210, a support tool for teaching. The experience of the Information Technologies Chair at UNED, Costa Rica

\section{BOT0210, uma ferramenta de apoio à docência. Experiência da Cátedra Tecnologias da Informação da UNED, Costa Rica}

\author{
Luis Monge Mata \\ Universidad Estatal a Distancia \\ San José, Costa Rica \\ lumonge@uned.ac.cr \\ (1) https://orcid.org/0000-0002-8958-0034 \\ Carolina Ávalos Dávila \\ Universidad Estatal a Distancia \\ San José, Costa Rica \\ cavalos@uned.ac.cr \\ (D) https://orcid.org/0000-0003-1754-8585
}

Recibido - Received - Recebido: 24 / 07 / 2020 Corregido - Revised - Revisado: 05 / 09 / 2020 Aceptado - Accepted - Aprovado: 09 / 09 / 2020

DOl: https://doi.org/10.22458/ie.v22iespecial.3196

URL: https://revistas.uned.ac.cr/index.php/innovaciones/article/view/3196

\begin{abstract}
Resumen: El avance tecnológico y las nuevas formas de comunicación demandan acciones diversas para gestionar la docencia universitaria, más aún con la situación que se vive en la actualidad tras un marcado distanciamiento social a causa de la pandemia por el virus responsable de la COVID-19. En este sentido, y valorando el alcance de herramientas tecnológicas más intuitivas, es posible considerar que la Inteligencia Artificial (IA) pueda ser complemento de la persona docente para agilizar los procesos de comunicación en la formación del estudiantado. La importancia del estudio consiste en socializar la experiencia del diseño e implementación de un chatbot en procesos de enseñanza-aprendizaje desarrollado durante la emergencia sanitaria para agilizar la labor del profesorado en la atención de consultas, facilitando con ello que se destine más tiempo a las labores académicas de la asignatura. Lo anterior fundamentó los intereses de la presente investigación de tipo exploratoria y descriptiva, a partir de la aplicación del chatbot llamado "BOT0210" en la Cátedra de Tecnologías de Información de la UNED de Costa Rica. La herramienta se utilizó por una muestra de 202 participantes, durante el primer cuatrimestre 2020. Entre los hallazgos obtenidos, se resaltó el uso frecuente y las impresiones positivas del "BOT02010" por parte de la población estudiantil y el profesorado en relación con la información facilitada sobre las actividades y la logística de la asignatura para la cual se creó el asistente virtual como apoyo a la gestión del personal docente.
\end{abstract}

Palabras clave: Aplicación informática, Inteligencia Artificial, comunicación, docencia, ayuda educativa, COVID-19

\begin{abstract}
Technological growth along with the new communication models call for different actions to manage teaching at a higher education level; specially now, considering the notable social distancing situation currently lived due to the pandemic caused by the virus responsible for COVID-19. In these sense, taking into account the extent of the most intuitive technological tools, it is possible to consider that Artificial Intelligence (Al) could actually be a teaching complement which accelerates communication processes in the training of students. The importance of this study lies at the root of socializing the experiences of designing and implementing a chatbot in the teaching-learning processes developed during the present health emergency in order to alleviate the teacher's attention hours, thus creating more time for the academic chores of their teaching subject. The
\end{abstract}


aforesaid, gives birth to the interest in this exploratory and descriptive research, based on the application of the chatbot called "BOT0210" in the Information Technology Chair of the UNED of Costa Rica. The tool was used by a sample consisting of 202 participants, during the first semester of 2020. Among the obtained findings and according to the information provided, the frequent use and positive impressions of the "BOT02010" were highlighted by the student population and the teaching staff regarding the activities and logistics of the subject for which the virtual assistant was created to support teaching staff management.

Key Words: Apps, Artificial Intelligence, communication, teaching, educational aids, COVID-19

Resumo: $O$ avanço tecnológico e as novas formas de comunicação exigem diversas ações para administrar o ensino universitário, ainda mais com a situação que estamos vivendo atualmente após um distanciamento social marcado devido à pandemia causada pelo vírus responsável pela COVID-19. Neste sentido, e valorizando o escopo de ferramentas tecnológicas mais intuitivas, é possível considerar que a Inteligência Artificial (IA) possa ser complemento ao professor para acelerar os processos de comunicação na formação dos estudantes. A importância do estudo consiste em socializar a experiência da concepção e implementação de um chatbot em processos de ensino-aprendizagem desenvolvidos durante a emergência sanitária para acelerar o trabalho do corpo docente na atenção de consultas, facilitando assim que mais tempo seja gasto nas tarefas acadêmicas da disciplina. Esta foi a base para os interesses da presente pesquisa exploratória e descritiva, baseada na aplicação do chatbot chamado "BOT0210" na Cátedra de Tecnologias de Informação da UNED na Costa rica. A ferramenta foi utilizada por uma amostra de 202 participantes durante o primeiro quadrimestre de 2020. Entre os resultados obtidos, destacou o uso frequente e as impressões positivas do "BOT0210" pela população estudantil e professores em relação às informações fornecidas sobre as atividades e logística da disciplina para a qual foi criado o assistente virtual para apoiar gestão do pessoal docente.

Palavras-chave: Aplicação informática, Inteligência Artificial, comunicação, docência, assistência educacional, COVID-19

\section{INTRODUCCIÓN}

La "nueva normalidad" en la que se desarrolló la docencia, a causa de la pandemia por el virus responsable de la COVID-19, representó un desafío para el sector educativo, desde la rápida adquisición de competencias de alfabetización mediáticas e informacionales (AMI), asumida por parte de los actores educativos en cuanto al "conocer" y "entender" el funcionamiento de diferentes herramientas tecnológicas y medios de comunicación, hasta el empoderamiento de la información para la construcción de contenido usado como recurso educativo por el estudiantado en diferentes asignaturas (Wilson, Grizzle, Tuazon, Akyempong \& Cheung 2011).

De una u otra forma, las experiencias de los últimos meses del personal docente, del estudiantado y de los padres de familia han permitido el logro de una mayor interacción de las herramientas tecnológicas y la diversificación de estas para propósitos educativos, más que informativos o de ocio. Con ello, se ha logrado la formación de una sociedad alfabetizada cada vez más responsable y comprometida con su realidad.

En la última década, el uso de la tecnología en la vida diaria se incrementó y no es de extrañar que tales cambios demanden mejoras sustanciales en el sector desde el cual se forma para la vida (Viñals \& Cuenca, 2016). Por tanto, la docencia, como actividad dialéctico-sistémica, tiene el reto de reinventarse y de nutrirse, apoyándose de una variedad de herramientas y recursos para ofrecer espacios de aprendizaje que respondan a diferentes realidades y necesidades de la sociedad, cada vez más disruptivas, en las que se desenvuelve el estudiantado.

Estudios recientes, con perspectivas de una educación futurista, realizados por la UNESCO (2020), visualizan la Inteligencia Artificial o (IA) como el bien común en los ecosistemas de educación. Para Barceló (2008) y Badaró, Ibañez \& Agüero (2013), la (IA) puede entenderse como un sistema computacional que emula la inteligencia del cerebro humano, puesto que muestra ciertas características asociadas a conductas humanas y algún grado de inteligencia. 
Por su parte, Rouhiainen (2018) señaló que una de las facilidades de los sistemas computacionales es que pueden aprender sin estar programados para esa función y los dividió en tres subconjuntos de aprendizaje: supervisado, no supervisado, y de refuerzo. De esta forma, tales funciones le permiten a la (IA) realizar predicciones o sugerencias a la persona, consideradas por el sistema computacional como importantes para atender el desarrollo de diferentes procesos en la cotidianeidad.

Con respecto a lo anterior, cada vez es más frecuente encontrarse con un material interactivo-predictivo, una aplicación intuitiva o un buscador inteligente que, además de brindar la información solicitada, guarde y organice los gustos de búsqueda y, en un mediano plazo, aprenda, recomiende o realice predicciones de la información que necesitamos. Tal es el caso de aplicaciones como Spotify, Facebook, Instagram, Pinterest, Amazon, o buscadores como Siri de Apple, Sound Hound de Android, Google, Bing, entre muchos otros.

Pues bien, desde la interacción en los ecosistemas educativos, según UNESCO (2020), se ve necesario diversificar la acción de la persona docente, no sustituyendo su rol primario como formador y guía, pero sí contando con estos apoyos tecnológicos desde la (IA), los cuales posibilitan una comunicación más inmediata, rápida y permanente al estudiantado que, de acuerdo con Lucking, Holmes, Griffiths y Forcier (2016), pueden convertirse en valiosas herramientas de apoyo para la labor del profesorado, por ejemplo: "en la recolección de datos de asistencia a clases o presentación de tareas dando seguimiento preventivo al estudiantado" (p.24).

En esta misma línea, se resalta el uso de los chatbot o asistentes virtuales, cuyos algoritmos están diseñados con el objetivo de imitar un diálogo entre el usuario y un asistente virtual. El cliente está dentro de una simulación que imita una conversación activa entre un emisor, quien da la información, y un receptor, que recibe el mensaje por medio de una interfaz basada, principalmente, en texto o mensajería con aplicaciones para enviar y recibir mensajes. A la vez, este tipo de programas informáticos que trabajan de forma independiente se pueden conectar por medio de plataformas de mensajería como Messenger de Facebook, WhatsApp o Microsoft Teams (Jee, 2019).

Esta tecnología no es reciente. El primer chatbot diseñado fue Eliza, en 1966, por Joseph Weizenbaum, que simulaba a una terapeuta (Darzentas, Vouros, Vosinakis \& Arnellos 2008). En 1972, otro chatbot llamado Parry simulaba el habla de un paciente con esquizofrenia paranoide. Sin embargo, no fue hasta el siglo XXI que, mediante el SmarterChild, las bases de este tipo de tecnología toman más fuerza.

Autores como Mancilla, Ebrat \& Capacho 2014 y Khan \& Das 2018, concuerdan en que estos asistentes virtuales o chatbots son programas informáticos que procesan la entrada en lenguaje natural de un usuario y generan respuestas inteligentes y relativas que son enviadas de vuelta al usuario. Así mismo, pueden implementarse como apoyos de ayuda, de comunicación o de información usando un Procesamiento de Lenguaje Natural o (PLN).

Para desarrollar un asistente virtual, es necesario utilizar los algoritmos que permitan determinar, de manera rápida y ágil, alguna solución a situaciones determinadas a partir de aprendizaje previo. Como ejemplo de lo anterior, López García, en el año 2019, incursionó en el diseño de un chatbot llamado "Gripebot", como propuesta informativa a ser usado en una campaña de educación de la salud para la gripe, con el objetivo de informar a la población de Navarra, España, sobre los tipos y patologías de gripe desarrolladas en las estaciones de otoño e invierno en los últimos años, a partir de datos obtenidos por la Organización Mundial de la Salud (OMS).

Entre los hallazgos del estudio, resaltó la viabilidad y la aceptación de la herramienta, tanto por el personal de salud como la población consultante, pues se evidenció la inmediatez al brindar la información. Se confirmó que es una herramienta de uso muy reciente, la cual "está ganando interés, evidenciando grandes ventajas en su uso y facilidad de interacción por parte de los usuarios" (López García, 2019, p.31). 
De acuerdo con Sheth (2016), existen varias plataformas para desarrollar "bots" conversacionales considerados como ecosistemas en línea. Algunas de las principales plataformas identificadas y analizadas como base para el diseño del modelo "BOT0210", fueron las siguientes:

- Facebook "Bots for Messenger": es una herramienta que permite a los usuarios de la red social desarrollar un chatbot integrado al Messenger de Facebook sin necesidad de ser un experto en informática. La herramienta tiene características como una aplicación para el envío y recepción de mensajes, uso de una serie de plantillas genéricas que pueden ser personalizadas y, además, permite la creación de una pantalla de inicio, única para cada bot.

- Pandorabots: esta empresa tiene una serie de servicios, por medio de plataforma web, que soporta el desarrollo de "bots". Para Culbertson (2016), esta aplicación permite el manejo de la plataforma en línea y el manejo de varios lenguajes de programación tales como Java, Python, Ruby, entre otros.

- Chatfuel: sus principales características son que posee interfaz fácil y amigable con el usuario, permite trabajar con una lógica de bloques de preguntas y respuestas de manera ordenada, es de integración sencilla con otras herramientas de desarrollo, facilita el seguimiento diario de la actividad del chat y, además, brinda opciones para sacar las estadísticas de uso.

Desde el marco contextual de la investigación, el incremento de las consultas hechas a la Cátedra durante la situación de emergencia sanitaria, la incertidumbre del estudiantado y profesorado ante el cambio de fechas para el desarrollo de procesos académicos, cierre de sedes universitarias y cambios en procedimientos institucionales para sobrellevar el cuatrimestre, instó a que la Cátedra tomara conciencia sobre la búsqueda de mecanismos que resultaran ser efectivos en la comunicación con el estudiantado para atender las consultas de forma inmediata durante veinticuatro horas los siete días de la semana. Gracias a esto, se aprovecharon las posibilidades que aporta la (IA) y se consideró un listado de consultas frecuentes realizadas a la Cátedra que sirvió para crear el diseño del "chatbot". Este fue programado para atender consultas administrativas y académicas sobre fechas específicas de entregas de trabajos, realización de exámenes, comunicados institucionales, información de la Cátedra y otra información propia de la asignatura Introducción a la Computación (0210) que, para ese momento, contaba con una población de 385 estudiantes matriculados durante el primer cuatrimestre del presente año.

Dicha iniciativa tuvo la intención de apoyar la gestión del personal docente, disminuir el exceso de consultas repetitivas generadas al chat, al correo y en foros de la plataforma educativa de Moodle, para que el profesorado pudiera concentrarse en otras labores de la asignatura requeridas a causa de la emergencia sanitaria, como la modificación de las pruebas ordinarias a pruebas digitales, capacitaciones para el uso de herramientas de comunicación como el Teams, Webex o ZOOM, diseño de video tutorías y otros materiales de apoyo a la mediación de la asignatura.

En este sentido, desde la situación de contexto detallada, el marco informativo y los antecedentes brindados, la investigación planteó como interrogante conocer si la herramienta "chatbot" puede funcionar como apoyo a la docencia en la asignatura Introducción a la Computación, para mantener una comunicación más efectiva con el estudiantado de la asignatura desde las ayudas educativas y de información brindadas.

El objetivo general consistió en el diseño de la herramienta "chatbot" como apoyo a la docencia en la asignatura Introducción a la Computación (0210) para agilizar la gestión docente durante el distanciamiento social por el virus responsable de la COVID-19. 
Así mismo, como objetivos específicos están:

- Conocer la frecuencia y el uso de la herramienta chatbot desde los aportes de la población estudiantil y el personal docente de la asignatura Introducción a la Computación en la interacción con el chatbot "BOT0210" durante el primer cuatrimestre del 2020.

- Identificar las ventajas de usar herramientas con algoritmos de (IA) como apoyo a la labor del profesorado en las asignaturas de la Cátedra Tecnologías de la Información.

\section{Del diseño de la herramienta}

El estudio se desarrolló en una primera fase experimental y de prueba para mejoras, durante el primer cuatrimestre del 2020. Su propósito es agilizar la labor del profesorado, dada la situación de distanciamiento social a causa de la emergencia sanitaria.

Desde el diseño de la herramienta chatbot, como primera etapa de diseño, se identificó el programa que asegurara un uso masivo entre el estudiantado y que fuera de fácil acceso. Por esa razón, se escogió la aplicación Chatfuel, la cual utilizó una integración con el servicio de mensajería "Messenger" de la red social de Facebook, información que se ampliará más adelante.

Seguidamente, se hizo un rastreo de las consultas académicas y administrativas frecuentes, por parte de la población estudiantil de la asignatura 0210, realizadas durante el segundo y tercer cuatrimestre del año 2019 y el primer cuatrimestre del año 2020, momento en que se inició con la situación de emergencia sanitaria. Este rastreo se dio mediante los correos electrónicos recibidos por el encargado de la Cátedra de Tecnologías de la Información y reenvío de mensajes por parte del personal docente. Para estos efectos, se realizó un diagrama de flujo que permitiera esquematizar el diseño del chatbot, ver Figura 1.

Figura 1. Diagrama de flujo del diseño del Chatbot "Bot0210"

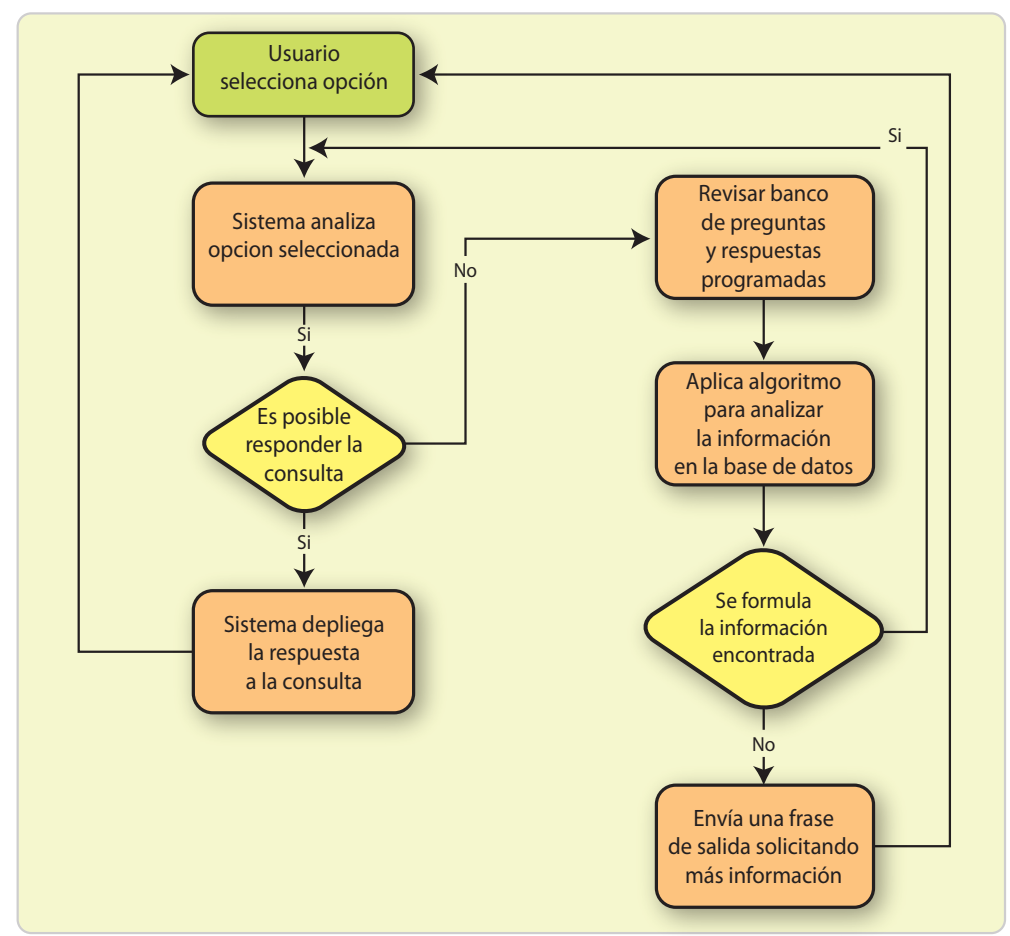

Fuente: Elaboración propia, 2020. 
Como segunda etapa de diseño, una vez consideradas las consultas de mayor frecuencia y la funcionalidad del diseño desde el diagrama de flujo, se revisó entre las plataformas investigadas para la creación de un chatbot (descritas en el apartado anterior), cuál de las mencionadas podría contar con características como libre acceso, fácil interacción, y ser usada por una población de al menos 400 estudiantes. Basado en estas características y en la operatividad de la herramienta, se seleccionó la plataforma "Chafuel" para realizar la implementación del "Bot0210", puesto que puede configurarse para usar el motor de entrega de mensaje del servicio de mensajería del "Messenger" de Facebook.

Esta se integró al servicio de mensajería del "Messeger" que, de una manera nativa, permitió configurar una opción gratuita para dar atención a una cantidad de usuarios que va de uno a 1000. En caso de precisar servicios a un número mayor de usuarios, se debe acceder a la versión de pago.

Para la validación de la herramienta, dado que es un primer esfuerzo realizado en fase experimental, se realizó desde dos vías:

- Con un equipo de profesores expertos en informática, quienes revisaron la versión inicial y realizaron aportes para la mejora, se examinó la pertinencia del programa y del Messenger al cual se ligó.

- Antes de su aplicación, la versión mejorada se socializó con el especialista de la Cátedra Tratamiento de la Información, quien revisó la viabilidad de las preguntas y formas de respuestas ofrecidas a la población estudiantil.

Estos procesos de prueba y validación se realizaron en los meses de marzo e inicios de abril del presente año.

A continuación, se presentan evidencias del ChatBot "Bot0210" en su fase final de diseño en la Figura 2:

Figura 2. Capturas de pantalla fase final de diseño. Chatbot "Bot0210"
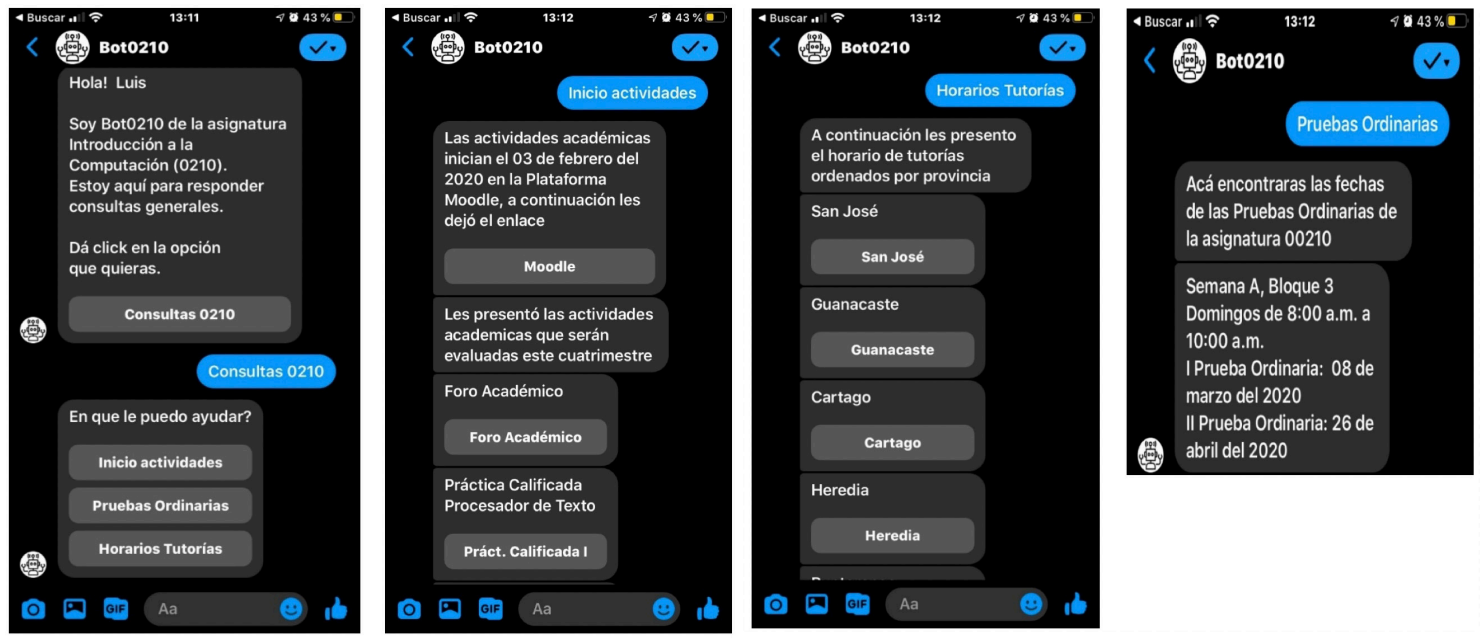

Fuente: evidencias del diseño del Chatbot, 2020. 


\section{MATERIALES Y MÉTODOS}

Desde su diseño, la investigación es de tipo exploratoria y descriptiva, ya que es la primera vez que la Cátedra incursiona en el diseño y la puesta en marcha de la herramienta usando la (IA) desde sus algoritmos, pues desde la teoría y experiencias previas en otros contextos, se puede dar detalle de las utilidades y facilidades de la herramienta. Por otro lado, a partir de los resultados logrados, se puede dar respuesta a la interrogante planteada en el estudio. Así mismo, este trabajo es de enfoque cuantitativo, ya que considera el alcance de los objetivos, el diseño del instrumento, el uso de técnicas de análisis y el tratamiento dado a la información recolectada (Bisquerra 2014).

El universo de estudio de la investigación fue de 385 estudiantes matriculados en la asignatura 0210 y de 15 docentes durante el primer cuatrimestre 2020, para un total de 400 sujetos. La muestra de 202 sujetos en total se obtuvo mediante una selección no probabilística e intencionada, de forma que se consideró al estudiantado quien, de forma voluntaria, dio uso, interactuó con la herramienta y contestó el instrumento a lo largo del primer cuatrimestre del presente año, al igual que la totalidad del personal docente. La caracterización de la muestra estuvo distribuida por 187 estudiantes, mayoritariamente adultos jóvenes, con un rango de edad de 18 a 28 años (70\%), donde el 75,2\% son mujeres y el 24,8\%, hombres, distribuidos en las siete provincias de Costa Rica. Desde su récord académico en la institución, se identificó que más del 70\% tiene cursados y aprobados más de tres cuatrimestres en la UNED y la mayoría pertenece a la Carrera de Administración de Empresas; lo cual evidenció que la asignatura se oferta principalmente para la carrera de la Escuela de Ciencias de la Administración, donde el género predominante es el femenino y se trata de una población con un conocimiento de medio a alto en el modelo de educación a distancia y aprendizaje en línea.

Por su parte, el personal docente estuvo conformado por 15 colaboradores de la Cátedra Tecnologías de la Información (12 hombres y 3 mujeres), quienes participaron en la investigación; todos ellos con grado de Maestría, más de tres cuatrimestres de trabajar en la Cátedra y con un rango de edad entre los 38 a 50 años.

Para la recolección de datos e impresiones, se usó la técnica de encuesta, mediante la aplicación de un cuestionario electrónico diseñado con la Plataforma de encuestas Limesurvey a disposición en la UNED. El instrumento llamado Herramientas de realidad virtual: explorando el Chatbot, se integró de tres partes o ítems: información sociodemográfica (5 elementos), uso de la herramienta (8 elementos), y recomendaciones para la mejora (pregunta abierta). Se conformó por 13 preguntas cerradas y una pregunta abierta, fue previamente validado por expertos en tecnología y educación y, una vez mejorado, se envió el enlace a estudiantes y personal docente.

En cuanto a los estadísticos de fiabilidad, el a de Cronbach evidenció que el instrumento obtuvo un valor de 0,87 en la valoración del ítem "uso de la herramienta", lo cual demostra una alta fiabilidad en el diseño del ítem y, con ello, alta confiabilidad de los datos obtenidos.

Seguidamente, para el análisis de datos, se trabajó con técnicas de análisis descriptivo y frecuencias usando la herramienta estadística SPSS. Posteriormente, la presentación de resultados se realizó mediante el análisis de las siguientes variables:

- Conocimiento de la herramienta: experiencias previas en la interacción con herramientas similares.

- Frecuencia y uso de la herramienta: considera aspectos como interacción con el chatbot, aprendizaje en el uso de la herramienta y utilidad del Bot0210.

- Ventajas del Bot0210 como herramienta de apoyo a la docencia: aportes realizados por el personal docente y estudiantado sobre la herramienta. 


\section{RESULTADOS}

El apartado presenta los resultados obtenidos de las variables: conocimiento de la herramienta, frecuencia y uso de la herramienta y ventajas del Bot0210 como herramienta de apoyo a la docencia, con la intención de dar respuesta a los objetivos planteados en la presente investigación.

\section{Conocimiento de la herramienta}

Las experiencias previas demarcan, generalmente, una gran diferencia en el desarrollo e implementación de cualquier iniciativa o innovación. Shank (2011) señalaba que, a medida en que se adquieren aprendizajes desde la práctica, el ser humano puede establecer conexiones en favor del funcionamiento y ejecución de determinada acción en diferentes escenarios. De ahí la importancia de esas experiencias, pues, de forma inconsciente, alguna idea se tendrá sobre el uso de algún dispositivo o herramienta, sobre todo en el área tecnológica.

Para la investigación, fue importante determinar el conocimiento previo que tenían las personas participantes en el uso de herramientas de (IA) tipo chatbot, por esa razón y con el propósito de indagar un poco sobre el conocimiento y uso de estos asistentes virtuales con formato de Messenger, se les consultó si habían tenido la experiencia de conocimiento sobre los "chatbots" de Facebook Messenger o algún otro similar. Los resultados obtenidos evidenciaron que más de 150 participantes ( aproximadamente 70\%) no habían interactuado o conocido de una herramienta de este tipo, lo que por un lado significó un aspecto novedoso para la Cátedra como experiencia piloto en la implemetación del Bot0210. Sin embargo, también generó la duda, pues podía ser probable que el nombre de la herramienta fuera lo que descolocó el conocimiento, no así el manejo instrumental de un Messenger de Facebook, como se apreciará más adelante con la variable de frecuencia y uso de la herramienta. Los datos sobre el conocimiento del chatbot se pueden apreciar en la Tabla 1.

TABLA 1

Conocimiento del chatbot

\begin{tabular}{|c|c|c|}
\hline Criterios & Frecuencia & Porcentaje \\
\hline Nunca & 71 & 35,1 \\
\hline Es mi primera vez & 80 & 39,6 \\
\hline Al menos una vez & 25 & 12,4 \\
\hline Anteriormente los había usado & 26 & 12,9 \\
\hline Total & 202 & 100 \\
\hline
\end{tabular}

Fuente: Datos del cuestionario en SPSS, 2020.

\section{Frecuencia y uso de la herramienta}

Se entiende la frecuencia como la cantidad de veces que se repite una acción en un período de tiempo determinado (Bisquerra, 2014). Estudios realizados por UNIMER, sobre medios de comunicación y redes sociales (UNIMER 2018), aportaron que, en nuestro país, así como en otras partes del mundo, herramientas como WhatsApp, YouTube, redes sociales como Facebook, Instagram, Twitter y, ahora, otras aplicaciones para crear avatares y videos como Tik-Tok, están entre las herramientas de mayor uso desde un nivel de información, comunicación y entretenimiento. Con la pandemia por el virus responsable de la COVID-19, el uso de estas herramientas se triplicó e involucró, también, su uso hacia lo formativo y lo laboral. 
A partir de los antecedentes con los que se contaba sobre la frecuencia de uso de estas herramientas, se consideró necesario consultar al estudiantado y al personal docente, sobre el tiempo que se le suele dedicar a programas de mensajería como Facebook o WhatsApp para hacer un estimado de la usabilidad que le podrían dar al Bot0210 e, incluso, valorar la viabilidad de un Bot0210 2.0 más adelante.

Entre los resultados, se evidenció una alta frecuencia en el criterio "Más de tres horas" (42,6\%) en el uso de herramientas de mensajería; el equivalente a más de 180 minutos de uso diario. Así mismo, se revisaron los criterios "De una a dos horas" y "Dos a tres horas", pues con ello fue posible determinar que aproximadamente un $46,1 \%$ está entre el rango de uso de 60 a más de 120 minutos por día en el acceso a estos medios de comunicación, lo cual coincidió con estudios realizados en el tema (UNIMER, 2018). Además, la investigación tuvo resultados favorables con respecto a la frecuencia en el uso, por lo que se estimó que el Bot0210 podría ser una herramienta con alto potencial de uso frecuente y sin presentar problemas en su operatividad o manejo, ya que su interfaz fue diseñada de forma similar a un Messenger de Facebook. Se pueden apreciar los detalles de la información en la Tabla 2.

TABLA 2

Tiempo de uso de mensajería FB Messenger o WhatsApp

\begin{tabular}{lcc}
\multicolumn{1}{c}{ Criterios } & Frecuencia & Porcentaje \\
No lo suelo usar & 2 & 1,0 \\
Menos de una hora & 21 & 10,4 \\
De una a dos horas & 46 & 22,8 \\
De dos a tres horas & 47 & 23,3 \\
Más de tres horas & 86 & 42,6 \\
Total & 202 & 100 \\
\hline
\end{tabular}

Fuente: Datos del cuestionario en SPSS, 2020.

Seguidamente, profundizando en el uso de la herramienta, se analizaron aspectos como la interacción con el chatbot, el aprendizaje en el uso de la herramienta y la utilidad del Bot0210. En ese sentido, se les consultó a las personas participantes si la interfaz de la herramienta les había resultado amigable y sencilla. Entre los hallazgos se obtuvo que 154 personas (más de un $75 \%$ de la muestra participante) indicaron estar entre los criterios de acuerdo y totalmente de acuerdo con que el Bot0210 sí era una herramienta de sencilla manipulación.

Respecto al aprendizaje en el uso de la herramienta, más del 80 \% evidenció estar de acuerdo en que el aprendizaje fue rápido y que no requirió una explicación extra para entender la dinámica de uso. Por otro lado, desde la utilidad del Bot0210, más de 180 personas coincidieron con que la herramienta de (IA) si contribuyó en atender dudas académicas de la asignatura. Además, indicaron que estarían dispuestos, en un mediano plazo, a usar la misma herramienta para solventar dudas de índole administrativo e informativo de la asignatura.

Finalmente, se les consultó sobre la posibilidad de implementar esta misma herramienta en otras asignaturas y el $80 \%$ de la muestra determinó que estarían de acuerdo con el planteamiento señalado. 


\section{Ventajas del Bot0210 como herramienta de apoyo a la docencia}

Se le consultó al personal docente y al estudiantado sobre qué tipo de recomendaciones realizarían al chatbot y qué ventajas notaron al usarlo. Se aportan algunas respuestas en breve, de las ventajas identificadas al usar el Bot0210:

"El uso fue fácil, el programa es sencillo. En lo personal, me gustó" (J. Arce, comunicación personal, 13 de abril del 2020).

"Me parece muy útil y de mucha ayuda para tener más claro y presente las fechas, tanto de las actividades como de los exámenes" (A. Benavides, comunicación personal, 14 de abril del 2020).

"Fue muy fácil cómo utilizarlo y me brindó de forma rápida respuesta a mi duda" (G. Rivas, comunicación personal, 14 de abril del 2020).

"Me parece muy útil, sé que ahí va a estar en cuanto tenga una duda" (R. Murillo, comunicación personal, 01 de mayo del 2020).

"La aplicación me parece una iniciativa muy buena para los estudiantes y así poder aclarar dudas más fácilmente, me gustaría que más materias usaran la aplicación para mejorar la comunicación" (C. Loria, comunicación personal, 18 de mayo del 2020).

Por otro lado, también se evidenció una serie de recomendaciones para la mejora del chatbot, entre las que se detallan las siguientes:

"Se podría implementar el uso de palabras claves para acceder con exactitud a la información que se requiere" (P. Sánchez, comunicación personal, 14 de mayo del 2020).

"Anunciar por otros medios como correos, mensajes de textos u otros, para que las personas tengan conocimiento de esta valiosa herramienta" (A. Valerio, comunicación personal, 14 de mayo del 2020).

"Que todas las materias tengan esta opción en la UNED. Que exista una manera para que las personas no videntes puedan utilizarla también. Que traiga las instrucciones de los trabajos a realizar, ya que la herramienta es muy útil y rápida para facilitar el acceso a instrucciones también" (S. Morales, comunicación personal, 14 de mayo del 2020).

"Me gustaría saber si es posible que el chatbot le envíe un mensaje de recordatorio al chat sobre el inicio o la finalización de las asignaciones, eso sería de gran ayuda" (A. Montiel, comunicación personal, 15 de mayo del 2020).

"Que publiquen actualizaciones o temas referentes al curso o carrera que se esté cursando. Más interacción con los estudiantes, más contenido, que agreguen temas informativos e importantes para el estudiante, que le sea de útil en el curso y a futuro" (K. Quirós, comunicación personal, 27 de abril del 2020).

Entre los aportes, resaltó la petición de una participante, quien recomendó se le incorporaran otros componentes para hacerlo accesible a la población no vidente, de forma que, además de poder ser leído, se pudieran ofrecer las respuestas de forma auditiva.

Lo anterior es un aporte muy significativo para el equipo que trabajó en el diseño del chatbot; de igual forma, fue un aspecto socializado durante su implementación, pensando en el mediano plazo en la versión 2.0, pues la idea de esta iniciativa tecnológica es que con los aportes y sugerencias de mejora se logre desde la Cátedra el diseño de un chatbot cada vez más ágil, intuitivo y accesible. Se busca que brinde apoyo, información, ayuda y orientación al estudiantado respecto a diferentes procesos académicos que se llevan a cabo en la asignatura 0210 mediante diferentes formas de comunicación; de esta manera, posibilitar una comunicación interactiva que le facilite al personal docente gestionar, de forma más ágil, su labor y la mediación de la docencia. 
El proceso investigativo, realizado en tiempos de emergencia sanitaria a causa del virus de la COVID-19 significó, para la Cátedra de Tecnologías de la Información, la posibilidad de explorar, identificar e implementar nuevas herramientas tecnológicas de apoyo a la labor educativa que ayudaran a agilizar la gestión del personal docente de la Cátedra. Desde la implementación de la (IA), fue posible brindar apoyo y acompañamiento al profesorado y estudiantado mediante una comunicación ininterrumpida, lo cual facilitó al personal docente efectuar otras acciones académicas propias de la asignatura que demandaban más tiempo, dada la situación de contexto mundial y cambios asumidos en el período académico de marzo a julio del 2020.

Los procesos de comunicación entre el estudiantado y el chatbot se incrementaron durante el cuatrimestre, debido a la situación de emergencia sanitaria y sus implicaciones (distanciamiento social y teletrabajo). La herramienta permitió aminorar las consultas al personal docente y a la Cátedra, principalmente aquellas vinculadas con diseño de tareas, dudas puntuales de la asignatura, fechas de entrega, realización de exámenes y otras afines con gestiones específicas en sedes universitarias. Es un recurso que, sin duda, puede ser replicado en otros espacios de la universidad.

Como principal ventaja de la herramienta de (IA), está la inmediatez de la respuesta que el estudiantado obtuvo en estos momentos de distanciamiento social, el "chatbot" proporcionó una respuesta automática a consultas que fueron programadas previamente.

La implementación de la herramienta "chatbot" y su integración con la plataforma de mensajería de una de las mayores redes sociales permitió que el estudiantado y el personal docente interactuaran con una herramienta de (IA) de fácil diseño, fácil programación, accesible y con posibilidades de respuesta inmediata, lo que la convierte en un complemento idóneo para la administración de la información y quehacer docente en una Cátedra Universitaria.

La experiencia del Bot0210 resultó ser una innovación para la Cátedra, que permitió, en momentos de emergencia sanitaria, identificar una necesidad de comunicación más rápida y permanente a lo largo del cuatrimestre para el estudiantado. Su implementación favoreció la disminución del tiempo en el que el docente y la Cátedra tardaban en atender consultas repetitivas de índole administrativo, académico y, así mismo, permitió gestionar esos esfuerzos en otros procesos de la labor docente.

Para una segunda etapa de implementación, se debe buscar una aplicación de software que permita adecuar el chatbot para estudiantes de necesidades especiales, tanto visual como auditiva; a la vez, es importante adaptar la herramienta para poblaciones indígenas, por medio del uso de sus lenguas autóctonas.

Además, se debe de ampliar la base de datos de las respuestas que el "chatbot" tiene programadas para brindar un mejor servicio al estudiantado; se pueden incluir los trabajos académicos que se deben de entregar durante el cuatrimestre, así como los temas de cada trabajo o hasta las rúbricas de evaluación.

A partir de la investigación realizada se sugieren otros temas vinculantes como: la (IA) en la evaluación de los procesos de enseñanza-aprendizaje, la estimulación del aprendizaje colaborativo mediante (IA) o, bien, sistemas de aprendizaje en línea que mediante (IA) orienten al estudiantado en relación con técnicas de estudio según sus estilos de aprendizaje. 


\section{REFERENCIAS}

Badaró, S., Ibañez, L. \& Agüero, M. (2013). Sistemas Expertos: Fundamentos, Metodologías y Aplicaciones. Ciencia y Tecnología. (13), 349-364. Recuperado de: https://doi.org/10.18682/cyt. v1i13.122

Barcelo, M. (2008). Una historia de la Infórmatica (1ª.ed). Barcelona, España. UOC.

Bisquerra, R. (2014). Metodología de la Investigación Educativa. (4ª .ed). Madrid España: La Muralla.

Culbertson, J. (11 de agosto 2016). Daily API RoundUp: Google Cloud Natural Language, IBM Watson Conversation, UniGraph, HERE, Inversoft. [Programmable Web]. Retieved from: https://bit. ly/3fTyAb6

Darzentas, J., Vouros, G., Vosinakis, S., \& Arnellos, A. (2008). Artifial Intelligence: Theories, Models and Applications. Alemannia: Springer-Verlag.

Jee, C. (2019, July 22). Best chatbot building platforms. Techworld. https://bit.ly/2Ate94F

Khan, R. \& Das, A. (2018). Build Better Chatbots: A Complete Guide to Getting Started with Chatbots. Bangalore India: Apress.

López García, A. (2019). Propuesta de diseño de un Chatbot informativo para la población sobre la gripe. Facultad de Salud. Universidad Pública de Navarra. [Tesis de grado]. Navarra-España. Recuperado de: https://bit.ly/39|tJge

Luckin, R; Holmes, W; Griffiths, M \& Forcier, L. (2016). Intelligence Unleashed: Anargument for Al in Education. Pearson Education, London. Retrieved from: https://bit.ly/3eXAXYM

Mancilla, A., Ebratt, R. \& Capacho, J. (2014). Diseño y construcción de algoritmos (1a.ed). Barranquilla Colombia: Universidad del Norte.

Rouhiainen, L. (2018). Inteligencia artificial (101 cosas que debes saber hoy sobre nuestro futuro). España. Alienta.

Shank, R. (2011). Teaching Minds. How Cognitive Science can save Our Schools. NY, United States of America: Teachers Collegue Press.

Sheth, B. (19 de mayo 2016). Bot Platforms-Easy and Quick Way to Build Advanced Bots. [Chatbots Magazine]. Retrieved from: https://bit.ly/2Z7uAOS

UNESCO (2020). Humanistic futures of learning. Perspectives from UNESCO Chairs and UNITWIN Networks. Paris France. Retrieved from: https://unesdoc.unesco.org/ark:/48223/pf0000372577

UNIMER (2018). Resumen del estudio RED 506 2018. Recuperado de: https://siles.cr/wp-content/ uploads/2019/04/Resumen-del-Estudio-RED-506-2018.pdf

Viñals, A. \& Cuenca, J. (2016). El rol del docente en la era digital. Revista Interuniversitaria de Formación del Profesorado. 30(2),103-114. Recuperado de: https://www.redalyc.org/articulo. oa?id=274/27447325008

Wilson, C., Grizzle, A., Tuazon, R., Akyempong, K., \& Cheung, C. (2011). Alfabetización mediática e informacional: currículum para profesores. UNESCO. https://unesdoc.unesco.org/ark:/48223/ pf0000216099 